\title{
PERAN GURU DALAM MENINGKATKAN MOTIVASI BELAJAR MURID MELALUI PEMBERIAN 'REWARD SUPER STUDENT' DI SEKOLAH DASAR KRISTEN 'B' SURABAYA
}

\author{
Natalia Dewi \\ Program Studi Pendidikan Guru Sekolah Dasar, \\ Universitas Kristen Petra \\ Jl. Siwalankerto 121-131, Surabaya \\ E-mail: Mynameisnataliadewi@gmail.com
}

\begin{abstract}
ABSTRAK
Dalam proses sebuah pendidikan pasti ada kalanya murid tidak mampu belajar dengan baik. Motivasi belajar membuat murid lebih mudah untuk belajar. Untuk membuat murid semangat belajar atau aktif dalam proses pembelajaran maka diperlukan guru yang memotivasi murid untuk belajar. Dalam penelitian kali ini menggunakan metode penelitian kualitatif deskriptif untuk mengetahui peran guru dalam meningkatkan motivasi belajar murid menggunakan Reward Super Student. Penelitian ini menggunakan teori behavioristic yang dicetuskan oleh B.F Skinner untuk mengetahui motivasi belajar murid. Guru memberikan Reward Super Student saat murid berhasil mencapai tujuan pembelajaran. Reward ini bisa didapatkan saat murid aktif bertanya, menjawab dan presentasi. Cara guru untuk menumbuhkan motivasi belajar murid didapatkan melalui 3 cara. Pertama, pembelajaran melalui proyek kelas. Kedua, kepemimpinan dan yang terakhir tugas tanggung jawab untuk meningkatkan motivasi belajar murid. Guru menggunakan ketiga cara tersebut untuk memotivasi belajar murid digabungkan dengan pemberian reward super student Dari hasil penelitian penggunaan Reward Super Student berhasil untuk memotivasi murid mau belajar.
\end{abstract}

Kata kunci: Guru Kristen, motivasi belajar, pendidikan Kristen, reinforcement, reward super student.

\begin{abstract}
In the process of an education there are times when students are not able to learn well. Learning motivation makes it easier for students to learn. To make students enthusiastic about learning or active in the learning process, a teacher is needed who motivates students to learn. In this study, a descriptive qualitative research method was used to determine the teacher's role in increasing student learning motivation using Super Student Rewards. This study uses the behavioristic theory that was coined by B.F Skinner to determine student learning motivation. The teacher gives Super Student Rewards when students succeed in achieving learning objectives. This reward can be obtained when students actively ask, answer and present. The teacher's way to foster student learning motivation is obtained in 3 ways. First, learning through class projects. Second, leadership and the last task is the responsibility to increase student learning motivation. The teacher uses these three methods to motivate student learning combined with giving super student rewards. From the research results, the use of Super Student Rewards is successful in motivating students to want to learn.
\end{abstract}

Keywords: Christian teacher, Christian education, learning motivation, reinforcement, super student reward.

\section{PENDAHULUAN}

Seorang guru memiliki peranan penting bagi murid untuk menumbuhkan semangat belajar dan mematuhi aturan yang ada di sekolah. Menurut (Harnika, Fitlayeni, \& Yatim, 2016) salah satu upaya yang dilakukan guru dalam proses pembelajaran itu terfokus kepada murid yang melakukan perilaku yang tidak diinginkan.

Dilansir dari Jawapos.com 3 Oktober 2019, sekitar 46,83 persen murid kelas empat SD kurang mampu membaca.
Anak yang tidak bisa membaca akan membuat mereka enggan pergi ke sekolah (Hikmia \& Salbiah, 2019). Menurut tempo.com 23 Juli 2019, jumlah jumlah anak usia 7-12 tahun di Indonesia yang tidak bersekolah berada di angka 1.228.792 anak (Tempo, 2019). Angka diatas adalah data yang dimiliki oleh Tim Nasional Percepatan Penanggulangan Kemiskinan (TNP2K). Dari data diatas bisa dilihat bahwa masih banyak anak yang tidak bisa bersekolah dikarenakan ekonomi yang kurang mampu.

Rulita (2016) mengatakan beberapa anak tidak dapat menikmati aktivitas bersekolah dengan 
baik, dan menolak untuk pergi ke sekolah dengan berbagai macam alasan seperti ketakutan, cemas, dan bahkan panik jika harus pergi ke sekolah. Oleh karena itu peran seorang guru sangat penting untuk membuat anak-anak mau berangkat ke sekolah dan memiliki minat belajar yang tinggi.

Ibu Guru Shella (nama opic) membuat kelas 2A di Sekolah Dasar "B" menjadi hidup. Guru ini berupaya maksimal agar murid di kelas tersebut tidak malas dan bosan. Beliau menggunakan alat yang dinamakan Reward Super Student untuk memancing murid agar memiliki motivasi belajar di kelas.

Peneliti melakukan penelitian di sekolah "B" yang dikenal sebagai salah satu sekolah unggulan yang berada di kota Surabaya. Sekolah ini juga terkenal dengan cara guru menghargai setiap murid dan cara guru memotivasi murid untuk mau belajar. Dengan demikian, peneliti ingin melihat bagaimana peran guru dapat meningkatkan motivasi belajar yang tinggi.

Selama ini penelitian yang dilakukan adalah pengaruh reward dan punishment terhadap motivasi belajar murid. Sedangkan untuk fokus ke peran guru dalam memotivasi belajar murid melalui pemberian Reward Super Student belum pernah ada yang meneliti. Oleh karena itu peneliti melakukan penelitian ini untuk mengetahui peran gurunya dalam meningkatkan motivasi belajar murid melalui pemberian Reward Super Student.

\section{LANDASAN TEORI}

\subsection{Pengertian Motivasi Belajar}

Dalam penelitian ini penulis menggunakan teori motivasi belajar menurut Uno. Uno (2019) mengatakan bahwa Sedangkan motivasi belajar adalah dorongan internal dan eksternal pada murid yang sedang belajar untuk mengadakan perubahan tingkah laku. Motivasi pada dasarnya dapat membantu dalam memahami dan menjelaskan perilaku individu yang sedang belajar. Motivasi dapat bersumber dari dalam diri individu itu sendiri (motivasi intrinsik) maupun dari luar individu (motivasi ekstrinsik). Menurut Uno (2019), ada beberapa peran motivasi belajar dalam proses pembelajaran, yaitu a) peran motivasi dalam menentukan penguatan belajar; b) peran motivasi sebagai memperjelas tujuan; dan c) motivasi sebagai alat menentukan ketekunan belajar.

\subsection{Pengertian Reward}

Penulis menggunakan teori Rewarding sebagai teori yang kedua.
Menurut Ernata (2017) reward adalah alat untuk mendidik anak supaya mereka merasa senang karena perbuatan atau pekerjaannya mendapat penghargaan. Tujuan pemberian reward yaitu agar murid lebih mengembangkan dan mengoptimalkan motivasi intrinsik murid untuk melakukan suatu perbuatan.

B.F Skinner (dalam Ernata, 2017) mengemukakan bahwa unsur yang terpenting dalam belajar adalah adanya penguatan (reinforcement) berupa reward dan hukuman (punishment). Skinner membagi dua macam reinforcement dalam bentuk positif dan negatif. Bentuk-bentuk penguatan positif adalah berupa hadiah seperti permen, kado, dan makanan, perilaku seperti senyum, menganggukkan kepala untuk menyetujui, bertepuk tangan, dan mengacungkan jempol, atau penghargaan berupa poin. Sedangkan bentuk negatif antara lain: menunda atau tidak memberi penghargaan, memberikan tugas tambahan atau menunjukkan perilaku tidak senang seperti menggelengkan kepala, mengerutkan kening, menunjukan muka kecewa.

\subsection{Peran Guru Sebagai Pendidik Kristen}

Hendricks (2013) mengatakan bahwa guru Kristen adalah sebagai stimulator dan motivator. Guru yang baik tidak berfokus pada apa yang mereka lakukan, tetapi pada apa yang sedang dilakukan muridnya. Hendricks (2013), mengatakan bahwa untuk menumbuhkan minat belajar murid guru perlu mengajari murid untuk berpikir. Menurut Hendricks (2013) tugas seorang guru Kristen adalah motivasi secara ekstrinsik untuk memicu timbulnya motivasi intrinsik dari dalam diri murid.

Brummelen (2015) mengatakan bahwa Allah memanggil guru-guru Kristen untuk membimbing anak-anak kepada pengetahuan yang berujung pada pelayanan kepada Tuhan. New Hope International (2016) mengatakan menjadi guru Kristen seperti perumpamaan menuntun orang buta. Seorang guru Kristen harus lahir baru untuk bisa mendidik setiap muridnya. Jika seorang guru Kristen tidak mengenal kebenaran maka akan terjadi tindakan hukuman di kelas tanpa ada rasa kasih. New Hope (2016), juga mengatakan bahwa menjadi guru Kristen haruslah seorang guru yang mengasihi, memotivasi, memperhatikan dan menolong murid.

\section{METODE PENELITIAN \\ 3.1 Desain Penelitian}

Jenis penelitian ini adalah penelitian kualitatif deskriptif karena penulis ingin mendeskripsikan bagaimana peran guru untuk meningkatkan motivasi belajar murid (lihat Affifudin, 2012). Penelitian ini dilakukan di Sekolah Dasar "B" Surabaya.

\subsection{Subyek Penelitian}

Subjek pada penelitian ini, peneliti menggunakan purposeful sampling yaitu Ibu Shella selaku Guru kelas 2A di Sekolah Dasar "B” Surabaya 
sejak tahun 2009. Sedangkan informan pendukung dalam penelitian ini adalah kepala sekolah atau orang yang menciptakan ide Reward Super Student.

\subsection{Metode dan Prosedur Pengambilan Data}

\subsubsection{Wawancara}

Wawancara dilakukan oleh peneliti untuk mendapatkan informasi mendalam tentang fungsi dan peran Reward Super Student yang tidak diperoleh melalui observasi di kelas (lihat Affifudin, 2012).

\subsubsection{Observasi}

Peneliti melakukan pengamatan terhadap aktivitas guru selama mengajar di dalam kelas. Peneliti mengamati cara guru berbicara, tindakan dan aktivitas guru bersama murid di kelas (lihat Affifudin, 2012).

\subsubsection{Dokumentasi}

Penelitian ini juga menggunakan metode dokumentasi untuk mendapatkan dan pengumpulan data dan informasi melalui pencarian bukti-bukti (lihat Affifudin, 2012).. Peneliti mengambil dokumentasi foto-foto yang mendukung sumber data. Foto-foto ini berupa tindakan guru saat memberikan Reward Super Student, murid antusias menjawab pertanyaan guru dan tindakan yang mendukung lainnya. Dokumentasi ini akan membantu peneliti untuk melakukan validasi data.

\subsection{Teknik Analisis Data}

Prosedur analisis data dalam penelitian ini dibagi menjadi beberapa langkah (lihat Basrowi \& Suwandi, 2008:207) :

1. Reduksi data. Pada tahap ini peneliti melakukan proses seleksi, pemfokusan, penyederhanaan, dan pengabstrakan dari semua jenis informasi yang mendukung data penelitian yang diperoleh dan dicatat selama proses penggalian data di lapangan.

2. Sajian data. Pada tahap ini, peneliti merakit informasi dalam bentuk deskripsi dan narasi yang lengkap.

3. Penarikan simpulan. Pada tahap ini, peneliti melakukan penafsiran terhadap hasil analisis dan interpretasi data.

4. Proses verifikasi. Pada tahap ini peneliti melakukan pengulangan langkah penelitian, yaitu dengan menelusuri kembali semua langkah penelitian yang telah dilakukan.

\subsection{Uji Validitas dan Reliabilitas}

Validitas data dalam penelitian ini diuji melalui triangulasi sumber data utama dengan wawancara informan. Dengan menggunakan triangulasi akan mengarahkan peneliti untuk mengumpulkan data dari berbagai sumber yang tersedia, karena data yang sama atau sejenis akan lebih mantap kebenarannya apabila digali dari sumber-sumber yang berbeda (lihat Affifudin, 2012).

Reliabilitas yang dipakai adalah reliabilitas pretest posttest. Peneliti melakukan wawancara beberapa kali dalam waktu yang berbeda untuk memastikan jawaban informan dan partisipan tetap konsisten. Reabilitas jenis kedua ini juga akan membantu peneliti untuk melihat data lebih akurat wawancara pertama dengan wawancara kedua kalinya (lihat Affifudin, 2012).

\section{ANALISA DATA}

\subsection{Implementasi Reward Super Student}

Reward ini berbentuk kartu bergambarkan bintang yang akan dibagikan kepada murid jika murid mencapai goal tertentu dalam proses pembelajaran. Reward Super Student ini dikumpulkan oleh murid setiap harinya. Murid akan menyimpan Reward Super Student ini sampai akhir semester. Setelah akhir semester murid akan menukarkan reward Super Student dengan alat alat tulis. Ada aturan jumlah reward yang bisa ditukarkan oleh murid. Jika kurang dari 5 reward super student murid tidak akan mendapatkan hadiah. Hadiah Reward Super Student dapat ditukarkan berdasarkan angka kelipatan 5 sesuai dengan perjanjian sekolah. Misalnya, 5 Reward Super Student akan mendapatkan 1 pensil, 10 Reward Super Student mendapatkan 2 pensil atau bisa memilih 1 pensil dan 1 penghapus. Sistem penukaran Reward Super Student membuat sangat antusias saat menukarkan reward yang mereka kumpulkan selama satu semester.

Reward Super Student dapat diberikan dengan syarat sebagai berikut. Pertama, Guru memberikan Reward Super Student sebagai apresiasi untuk murid yang aktif dalam pembelajaran. Kedua, Reward Super Student dapat diberikan kepada murid yang telah menyelesaikan tugas dan tanggung jawab dengan baik. Ketiga, Reward Super Student tidak diberikan secara Cuma-Cuma, harus ada sesuatu yang murid kerjakan atau lakukan. Murid antusias untuk mendapatkan Reward Super Student karena kebutuhan dasar manusia (lihat Abraham Maslow, 1970).

Reward Super Student diberikan saat murid telah melakukan tindakan perilaku positif dalam hal belajar, dan juga saat murid bertanya, menjawab pertanyaan guru atau memiliki inisiatif dalam kegiatan pembelajaran guru. Pada awal-awal pengamatan murid yang mendapatkan Reward Super Student hanya tidak lebih dari 10 murid, karena murid masih belum bisa beradaptasi dengan proses pembelajaran guru. Pada minggu-minggu berikutnya murid sudah mulai paham bagaimana cara mendapatkan Reward Super Student. Murid memacu dirinya untuk berusaha mengikuti proses pembelajaran dengan inisiatif menjawab, 
mengajukan diri untuk bercerita, melakukan eksperimen dengan benar dan sebagainya.

\subsection{Peran Guru dalam} Meningkatkan Motivasi Belajar Murid Untuk meningkatkan motivasi belajar murid di kelasnya, Ibu Shella memiliki beberapa cara, yaitu melalui proyek kelas, melalui kepemimpinan yang sengaja didesain untuk murid, dan melalui tugas dan tanggung jawab yang diberikan kepada murid.

Cara yang pertama adalah melalui proyek kelas. Pemberian proyek kelas menolong murid untuk mengatasi kesulitan belajar. Proyek yang diberikan oleh guru membuat murid tidak malas untuk belajar. Dari hasil wawancara, saat diadakan proyek kelas respon murid menjadi aktif, berpikir logis, kreatif, kerjasama dan berpikir kritis. Guru membagi murid dalam beberapa kelompok agar semua murid terlibat aktif bukan pasif. Dengan demikian, proyek kelas membantu murid untuk termotivasi belajar.

Saat mereka termotivasi untuk menjadi murid yang aktif, murid akan mendapatkan Reward Super Student. Guru akan memberikan Reward Super Student saat murid dapat mengikuti proses pembelajaran dengan baik. Pada saat murid berani mempresentasikan hasil pekerjaan mereka akan mendapatkan 1 Reward Super Student. Dengan reward tersebut murid semakin aktif dan termotivasi untuk belajar.

Dari pengamatan peneliti, reward yang diberikan oleh guru sangat efektif untuk membuat murid mau aktif dalam proses pembelajaran. Tidak ada murid yang tidak tertarik untuk mengikuti pembelajaran melalui proyek kelas. Murid sangat semangat ditambah lagi dengan stimulus yang guru berikan.

Cara yang kedua adalah melalui kepemimpinan yang dilakukan dengan memberikan kesempatan bagi murid untuk menjadi pemimpin kelas. Murid melakukan tugas dan tanggung jawabnya sebagai pemimpin selama seminggu. Pemilihan ini berdasarkan inisiatif murid yang mengajukan dirinya dan murid yang sengaja ditunjuk guru menjadi pemimpin. Guru memberi kesempatan kepada murid yang pendiam untuk menjadi pemimpin kelas untuk membantu murid tersebut untuk aktif dan menumbuhkan rasa ingin belajar. Menurut Ibu Shella, murid yang pendiam jika tidak diberi kesempatan terlebih dahulu mereka akan diam pasif.

Murid pendiam tersebut akan berpikir bahwa dia tidak perlu menjadi pemimpin sudah ada murid lain yang lebih ingin menjadi pemimpin.
Reward Super Student memiliki hubungan dengan kepemimpinan dan motivasi belajar. Saat murid melakukan tugas kepemimpinan selama seminggu dengan baik guru akan memberikan Reward Super Student. Hal ini mempengaruhi murid untuk termotivasi belajar menjadi pemimpin agar mendapatkan Reward Super Student.

Cara yang ketiga adalah melalui tugas dan tanggung Jawab. Sebelum memberikan tugas dan tanggungjawab, guru menjelaskan tujuan dari proses pembelajaran sehingga murid akan mengerti tugas dan tanggung jawab mereka selama di sekolah. Misalnya mereka akan belajar penjumlahan, guru akan menjelaskan mengapa belajar penjumlahan dan setelah kelas selesai hasil yang diharapkan guru apa. Saat murid mengetahui tujuannya mereka belajar matematika penjumlahan, mereka akan berusaha agar bisa melakuan penjumlahan.

Peneliti mengamati bahwa tugas dan tanggung jawab dapat membuat murid menggali potensi yang ada di dalam dirinya. Misalnya murid yang pendiam dan malu untuk bercerita, saat diberikan tugas bercerita dia akan berusaha dan ternyata dia memiliki bakat untuk bercerita. Selama ini murid pendiam karena mungkin tidak diberikan kesempatan.

\subsection{Pandangan dari Iman Kristen}

Dalam Roma 5:8-10 menyatakan bahwa ini kita mendapatkan sebuah reward keselamatan dari Tuhan. Begitu juga saat murid berusaha mengerjakan dan belajar dengan baik maka ia bisa mendapatkan reward dari guru. Di kelas murid akan berusaha bertanya saat tidak mengerti supaya dia benar-benar mengerti pelajaran dan mendapatkan reward.

Dalam ayat tersebut juga digambarkan bahwa Yesus memberikan reward kepada kita dalam bentuk keselamatan. Hadiah yang Tuhan berikan melalui pengorbananNya mati di kayu salib. Sedangkan dalam konteks Reward Super Student hadiah adalah murid mendapatkan Reward Super Student atas usaha belajar dengan keras. Murid mendapatkan reward sesuai atas usaha yang mereka lakukan.

Menurut pandangan Alkitab untuk mendapatkan reward harus ada usaha yang dikeluarkan (lihat Filipi 3:14). Jika murid tahu tujuan belajar, maka mereka akan berusaha mencapai target yang ingin dicapai dan sebagai bonusnya akan mendapatkan Reward Super Student atas usaha yang dikeluarkan.

Pendidikan Kristen menekankan bahwa apapun yang murid lakukan fokusnya untuk Tuhan bukan untuk mengejar Reward Super Student (lihat Kolose 3:23-24). Memang murid akan mendapatkan Reward Super Student jika berhasil melakukan dari tujuan pembelajaran. namun seorang guru perlu mengubah mindset murid bahwa 
mereka belajar dan memberikan yang

terbaik untuk Tuhan Yesus.

\section{KESIMPULAN DAN SARAN}

\subsection{Kesimpulan}

Peran yang dilakukan guru untuk meningkatkan motivasi ada 3 cara, yaitu menggunakan proyek kelas untuk meningkatkan motivasi belajar murid, melalui kepemimpinan, melalui tugas dan tanggung jawab. Proyek kelas sangat efektif diterapkan untuk meningkatkan motivasi belajar murid. Melalui kepemimpinan murid termotivasi untuk belajar hal baru, menjadi teladan bagi temannya, dan menjadi pemimpin inisiatif belajarnya tumbuh. Tugas dan tanggung jawab membuat murid merasa dihargai dan dipercaya oleh guru. Sehingga respon yang murid keluarkan adalah belajar dengan sungguh-sungguh. Penggunaan Reward Super Student untuk meningkatkan motivasi belajar murid berjalan dengan baik. Dilihat dari hasil pengamatan dan wawancara, murid menunjukan respon positif saat diberikan Reward Super Student. Bahkan reward ini menolong untuk mengubah murid yang pasif belajar menjadi aktif untuk belajar. Sehingga dapat disimpulkan bahwa reward ini memiliki peranan penting dalam memotivasi belajar murid.

\subsection{Saran}

a. Bagi peneliti selanjutnya, sebaiknya topik Reward Super Student diteliti di sekolah lain dengan level ekonomi lebih tinggi atau lebih rendah untuk membandingkan respon siswa.

b. Bagi guru-guru yang sedang kesulitan untuk memotivasi murid belajar dapat mencontoh apa yang dilakukan oleh Ibu Shella.

\section{DAFTAR REFERENSI}

Agus R, A. H. (2015). Strategi pengelolaan kelas dalam proses pembelajaran. Jurnal Pendidikan Pedagogik, 03(1), 1-12. Retrieved from https://ejournal.unuja.ac.id/index.php /pedagogik/article/view/100.

Amali, R. (2016). Teori behavioristik. Sidoarjo: Universitas Muhammadiyah.

Brummelen, H.V. (2016). Berjalan bersama Tuhan di dalam kelas. Surabaya: ACSI.

Ernata, Y. (2017). Analisis motivasi belajar peserta didik melalui pemberian reward and punishment di SDN Ngaring $05 \mathrm{Kec}$. Gadungsari Kab. Blitar. Jurnal Pemikiran Dan
Pengembangan Sekolah Dasar (JP2SD), 5(2), 781-790. https://doi.org/10.22219/jp2sd.v5i2.4828

Familus. (2016). Teori Belajar Aliran Behavioristik Serta Implikasinya Dalam Pembelajaran. Riau: Universitas Negeri Padang.

Hapsari, D. I., \& Airlanda, G. S. (2018). Penerapan project based learning untuk meningkatkan motivasi belajar matematika peserta didik kelas V. AULADUNA: Jurnal Pendidikan Dasar Islam, 5(2), 154-161. https://doi.org/10.24252/auladuna.v5i2a4.201 $\underline{8}$.

Harnika, N. S., Fitlayeni, R., \& Yatim, Y. (2016). Strategi guru dalam mengontrol perilaku siswa kelas XI IPS 4 di SMA Negeri 1 Pancung Soal Kabupaten Pesisir Selatan. Jurnal Ilmiah Mahasiswa STKIP PGRI Sumatera Barat, 1-11. Retrieved from $\underline{\text { http://jim.stkip-pgri- }}$ sumbar.ac.id/jurnal/download/1432.

Hendricks, H.. (2013). Mengajar untuk mengubah hidup. Jakarta: PT Gloria Usaha Mulia.

Hergenhahn, B.R. \& Olson, M H. (2015). Theories of learning ( $7^{\text {th }}$ ed.). Jakarta: Kencana Prenada Media Group

Hikmia, Z., \& Salbiah, N. A. . (2019). 46,5 persen siswa SD kelas 4 dikatakan kurang mampu membaca. Jawa Pos. Retrieved from https://www.jawapos.com/nasional/pendidika n/03/10/2019/465-persensiswa-sd-kurangmampu-membaca/

Idzhar, A. (2016). Peranan guru dalam meningkatkan motivasi belajar siswa. Jurnal Office, 2(2), 221-228. https://doi.org/10.26858/JO.V2I2.2956

Nahar, N. I. (2016). Penerapan teori belajar behavioristik dalam proses pembelajaran. NUSANTARA : Jurnal Ilmu Pengetahuan Sosial, 1(1), 64-74. Retrieved from http://jurnal.umtapsel.ac.id/index.php/nusantara/article/view/ $\underline{94}$

Nugrahani, F. (2014). Metode penelitian kualitatif. Jakarta: Gramedia

Partisipasi pendidikan naik tapi jutaan anak Indonesia masih putus sekolah.. (2019, July 23) Tempo. Retrived from https://www.tempo.co/abc/4460/partisipasipe ndidikan-naik-tapi-jutaan-anak-indonesia$\underline{\text { masih-putus-sekolah. }}$

Atton, M. Q. (1990). Qualitative evaluation and research methods. Newbury Park: Sage 
Raco, J.R. (2010). Metode penelitian kualitatif. Jakarta: PT Gramedia Widiasarana Indonesia

Achmawati, E. (2015). Pengaruh reward and punishment terhadap prestasi belajar murid SD Muhammadiyah 10 Tipes Surakarta tahun ajaran 2014/2015. Undergraduate thesis. Fakultas Keguruan dan Ilmu Pendidikan.Universitas Muhammadiyah Surakarta. Retrieved from http://eprints.ums.ac.id/id/eprint/353 $\underline{14}$

Rafiqah, M., Yusmansyah, Y., \& Mayasari, S. (2013). Pengaruh motivasi belajar terhadap prestasi belajar. ALIBKIN (Jurnal Bimbingan Konseling), 2(2), 9 p. Retrieved from http://jurnal.fkip.unila.ac.id/index.ph p/ALIB/article/view/1661

Rusman. (2015). Model-model pembelajaran: Mengembangkan profesionalisme guru. Jakarta: Rajawali Pers/PT Raja Grafindo Persad

Salbiah, N.A. (Ed). 46,5 persen murid SD kelas 4 dikatakan kurang mampu membaca. Jawa Pos. Retrived from https://www.jawapos.com/nasional/p endidikan/03/10/2019/465-persensiswa-sd-kurang-mampu-membaca/

Siti, S. (2015). Upaya guru dalam meningkatkan motivasi belajar siswa. Jurnal Pendidikan Ekonomi UM Metro, 3(1), 73-82. Retrieved from https://www.ojs.fkip.ummetro.ac.id/i ndex.php/ekonomi/article/viewFile/1 $\underline{44 / 115}$

Uno, H.B.(2010). Teori motivasi \& pengukurannya: Analisis di bidang pendidikan. Jakarta: PT. Bumi Aksara.

Zaini, R. (2014). Studi atas pemikiran B.F. Skinner tentang belajar. TERAMPIL: Jurnal Pendidikan Dan Pembelajaran Dasar, 1(1), 118-129. https://doi.org/10.24042/terampil.v1i 1.1309 